\title{
DOENCA E CURA: SISTEMA MÉDICO E REPRESENTACÃOO ENTRE OS HUPDË-MAKU DA REGIÃO DO RIO NEGRO, AMAZONAS
}

\section{Renato Athias}

\section{Universidade Federal de Pernambuco - Brasil}

Resumo: Este trabalho analisa os itinerários terapêuticos com relação às doenças contagiosas e apresenta uma síntese do sistema médico dos Hupdë-Maku. Os dados desta pesquisa foram colhidos através de trabalho de campo realizado no Rio Negro durante o ano de 1997. A população indígena da região está em contato com as frentes de colonização desde o século XVII e tem-se notícias que ocorreram inúmeras epidemias que dizimaram parte da população. Mesmo existindo - de uma forma precária - serviços de saúde na região e os próprios índios já conhecem a "eficiência" do sistema médico ocidental, desta forma existe uma escolha seletiva do intinerário terapêutico a ser seguido pelos próprios indígenas. Como se dá esta escolha? Qual é o papel do pajé(s)? E como os pajés operam no interior deste sistema? Até então se tem referido em doenças de índios e doenças de branco como categorização na seleção do itinerário terapêutico. No entanto, a lógica na elaboração de representações das assim chamadas doenças-de-branco apenas poderá ser compreendida a partir do entendimento do mito e da cosmologia que, em última instância, estrutura as relações no interior do grupo étnico e no conjunto das relações interétnicas da bacia do Alto Rio Negro. Portanto, a compreensão da existência de interpretações, justapostas ou paralelas, dentro de categorias como doença-de-branco e doenças-de-índios não é apoiada, na prática e nem pela a escolha dos processos terapêuticos.

Abstract: This paper analyses the therapeutic process regarding contagious diseases and it also presents a synthesis of the Hupdë-Maku's medical system. The data presented were collected through fieldwork accomplished in Rio Negro during the year of 1997. The indigenous population of this area have been in contact with the colonisation fronts since the $17^{\text {th }}$ century. There is information of countless epidemic diseases 
since this contact, which has decimated the population. Although currently there are health services in the area - precariously provided by government agencies - and therefore the Indians already know the "efficacy" of the western medical system. The research points out the indigenous selective choice of the therapeutic resources. How is this choice made? What is the role of the shaman? And how does the shaman operate inside this system? Researchers have been referring to two categories in the selection of the therapeutic itinerary: diseases- of-Indians and disease-of-white. However, the logic of the representations about the disease-of-white can only be understood throughout their myths and cosmology, in the context of inter-ethnic relationships in the Rio Negro basin. Therefore, the understanding of the categories as disease-ofwhite and disease-of-Indians, which may be juxtaposed or parallel, are not based on social practices, nor on the choice for therapeutic resources.

\section{Introduç̃o}

Este trabalho tem um caráter exploratório. As questões aqui colocadas surgiram a partir de trabalho de campo realizado entre os Hupdë-Maku ${ }^{1}$ habitantes da região interfluvial do Rio Tiquié e Rio Papuri, afluentes da margem esquerda do Rio Uaupés na região do Alto Rio Negro, Estado do Amazonas. Em $1984^{2}$ tive a oportunidade de realizar um levantamento epidemiológico preliminar entre estes índios e, naquela ocasião, notou-se um índice elevado de incidência de tuberculose. Recentemente (1996) realizamos outro levantamento $^{3}$ da situação de saúde destas populações. Não se pode obter, devido a precariedade do sistema de informação, dados estatísticos que confirmassem o aumento ou a redução da tuberculose nestes últimos 12 anos. Parece-nos ainda elevado o número de indígenas portadores de tuberculose, em toda área.

Quando realizávamos este levantamento soubemos que alguns Hupdë foram levados para fora de sua área a fim de receberam tratamento de tuberculose.

\footnotetext{
Hup = gente dë =sufixo de plural. Foneticamente seria húp'd^.

Cf. Athias, Selau e Verdum (1984).

3 Cf. Oliveira et al. (1997).
} 
A maioria destes, pelo que fomos informados, abandonou o tratamento pela metade. ${ }^{4}$ Com o intuito de compreender a razão deste abandono do tratamento fui levado a procurar entender como os Hupdë percebem e representam as doenças contagiosas, aquelas introduzidas através do contato com sociedade nacional, ou como os Hupdë as chamam: teng'hóidë pé'é (literalmente: doenças do barulho-da-madeira-queimada-que-estala). ${ }^{5}$ Portanto, este trabalho representa um começo de uma sistematização sobre representação de saúde e doença, entre as populações Hupdë.

É importante salientar que na região conhecida como Alto Rio Negro vem acontecendo um processo de aculturação. ${ }^{6}$ Os povos indígenas envolvidos neste processo fazem parte dos grupos lingüísticos: Maku, Tukano e Aruak. Esse processo fez com que as populações indígenas desta região interagissem e procurassem reelaborar através de sua mitologia, memória e tradição oral elementos que justificassem sua presença neste território como diferenciados como povos distintos, cada um com sua identidade e, ao mesmo tempo, integrados no contexto ecológico da região.?

Estas populações estão em contato com as frentes de colonização desde o século XVII e têm-se notícias que ocorreram inúmeras epidemias de sarampo, varíola e gripes que dizimaram parte da população. ${ }^{8}$ Apesar de existir diferenças significativas entre os diversos sistemas médicos dos Tukano, Aruak e Maku, nota-se a presença de elementos comuns, entre eles. Em geral nos processos terapêuticos e na forma como os pajés, operam neste sistema; eles são vistos e percebidos pelos diversos grupos indígenas, como o agente mediador capaz de oferecer um diagnóstico e posteriormente a cura. Outro elemento comum - entre os Hupdë-Maku, Tukano e Aruak - diz respeito à utilização

\footnotetext{
4 O tratamento tem a duração mínima de 6 meses. E isto já constitui uma das dificuldades. Pois quando são levados para fora de suas aldeias não querem permanecer distantes todo este tempo.

Para melhor informação sobre estas epidemias veja: Buchillet (1995).

5 Teng'hóidë é como os Hupdë chamam os não-índios. É uma alusão ao fato do barulho ser parecido ao som de um tiro de espingarda.

6 Sobre este processo aculturativo ver Athias (1995).

7 Sobre isso ver Athias (1995).

8 Para melhor informação sobre estas epidemias veja: Buchillet (1995).
} 
da palavra como um elemento importante ou como agente mediador em todos os processos terapêuticos. Podemos também notar que todos os grupos indígenas usam, em suas línguas, o mesmo conteúdo semântico para denominar as doenças, chamadas "do branco". Neste processo aculturativo os povos indígenas tiveram que elaborar um conhecimento específico sobre estas doenças introduzidas. Na realidade, todos são unânimes em afirmar que embora não conheçam a etiologia destas doenças, têm uma explicação mitológica sobre o seu aparecimento.

A vasta experiência que os indígenas têm em relação às doenças infecciosas, introduzidas através do contato, faz que todos identifiquem o rio (meio de comunicação), como um veículo de transmissão destas afecções. A "doença vem pelo rio” ou "junto com as mercadorias dos teng'hói vem a gripe” dizem os Hupdë. Mais adiante, a título de informação, descrevemos o estado atual de saúde em que estas populações se encontram.

Desde a chegada dos atuais missionários na região, por volta de 1916, foram introduzidas enormes mudanças no sistema econômico-político-social dos grupos indígenas. A maneira como foram feitas estas mudanças afetou consequentemente o equilíbrio existente na região fruto de enormes negociações entre os diferentes grupos indígenas com relação às concepções de saúde e doença. Não se quer dizer, aqui, que os novos conceitos ou concepções de saúde e doença introduzidas, baseadas num discurso eminentemente higienista discriminador, foi aceito pacificamente pelos índios. Esta concepção, trazida pelos missionários, pôs fim a um número significativo de práticas xamânicas, consideradas como “coisas do diabo”. Muitos pajés tiveram que se esconder e aceitar a proibição de não praticar pajelança.

Apesar de todos estes anos de uma presença missionária forte, pode-se ainda perceber que a medicina indígena não foi destruída. Na realidade, convive, até certo ponto pacificamente, e talvez, diríamos, complementam-se os dois sistemas médico (ocidental e indígena). ${ }^{9}$ Como enfatizamos em relatórios

9 Durante o levantamento sobre a situação atual de saúde (veja nota 3) foi possível realizar três oficinas com os atuais Agentes Indígenas de Saúde e Lideranças sobre o entendimento das noções de saúde e doença vigentes na região. Durante estas oficinas os próprios AIS enfatizaram a importância deste sistema médico indígena a necessidade também de aprender mais sobre este sistema. 
anteriores, estas mudanças no sistema indígena, resultou na deterioração das condições sanitárias existentes hoje, em praticamente todas as aldeias devido ao sistema de casas e rigidez introduzidas pelos missionários. As alternativas colocadas em prática na região, como os hospitais das missões, postos médicos, agentes de saúde indígenas reforçando o sistema médico ocidental não está dando uma resposta sustentável ao estado de saúde em que se encontram estas populações. Existe, no entanto, uma cobrança urgente por parte dos Agentes Indígenas de Saúde (AIS), Tukano e Aruak (não existe Agente de Saúde entre os Hupdë), com relação à melhoria da situação de saúde na região bem como um reconhecimento da medicina indígena.

De fato, existe uma procura de remédio "branco" entre os indígenas e refere-se quase exclusivamente à medicação analgésica, sintomática e às verminoses. É o que mais pedem. Em novembro e dezembro de 1996 foram realizados três encontros de agentes de saúde e lideranças para se discutir a noção que estes têm de doença e saúde em função da implantação de um projeto de saúde. ${ }^{10}$ Num universo de 32 agentes indígenas de saúde presentes a estes encontros, 20 responderam que a medicação que mais sentem falta é a dipirona e AAS. Muitos dizem que preferem tomar os remédios dos brancos para passar a dor que utilizar o que normalmente usavam que é uma planta conhecida como pinu-pinu, um tipo de urtiga que, passando no corpo, sente-se um alivio das dores. Em outras palavras, existe uma procura seletiva: do momento e aonde procurar o medicamento. Por outro lado, dificilmente um indígena mordido de cobra vai procurar tratamento no posto de saúde ou hospital, pois acreditam na eficiência de seu próprio remédio. No sistema de saúde em vigor no lado colombiano, com as mesmas etnias, foi resolvido de uma certa forma esta dicotomia: nos postos de saúde existem pajés (pagos pelo governo) para atenderem em primeiro lugar os pacientes que procuram, e em seguida passar ao Agente de Saúde, de acordo com as informações dos próprios índios.

Este trabalho insere-se num contexto onde a medicina indígena sofre mudanças significativas a partir do contato e portanto o conhecimento vai

${ }^{10}$ Este projeto de saúde está em andamento através de um convênio entre a Associação Saúde Sem Limites/ Health Unlimited e a Federação das Organizações Indígenas do Rio Negro. 
transformando-se, reelaborando-se na medida em que vão introduzindo-se elementos novos dentro de um espaço social onde as relações são mais intensas. Especificamente dentro do contexto do Alto Rio Negro, esta reelaboração é intensa e significativa, pois varias etnias participam neste processo. As questões e os elementos aqui apresentados reafirmam que todo o conhecimento relacionado ao corpo, saúde e doença é construído culturalmente, negociado e renegociado num processo dinâmico através do tempo (na mitologia) e do espaço social (território e contexto ecológico). Pretende-se aqui, argumentar que a classificação de doenças-de-brancos e doenças-de-índios não é uma categorização simples de se realizar entre as populações indígenas. Estas fazem parte de um conjunto mais amplo de interpretações e representações dentro dos contextos cosmogônicos. O que se espera é que as instituições que são responsáveis pela saúde nas áreas indígenas possam oferecer um serviço de saúde utilizando-se deste conhecimento e sejam compreendia pela maioria da população indígena.

\section{Quem são os Hupdë}

Os Hupdë da família lingüística Maku, habitam tradicionalmente o território da região interfluvial do Rio Papuri e Rio Tiquié afluentes da margem direita do Rio Uaupés. Estão espalhados em mais de 35 aldeias (grupos locais) estimados em um total de 1300 indivíduos. Existem outros grupos, conhecidos também, como Maku na bacia hidrográfica do Rio Negro. Todos eles, com sua língua própria, praticamente vivendo no interior da floresta nos pequenos igarapés.

Os Yohupdë, por exemplo, vivem nos igarapés da margem direita do Rio Tiquié (Castanho, Samaúma, Cunuri e Ira) são menos numerosos e quase não têm contato com os Hupdë. Os Bará-Maku ou Cácua vivem nos Igarapés da margem esquerda do Rio Papuri em território colombiano. Ainda em território colombiano, estão os Nukak nos rios Guaviari e Enírida. Os Dâw, conhecidos popularmente como Kamã, vivem nos arredores de São Gabriel da Cachoeira, porém seu território tradicional são os igarapés do Rio Curicuriari, (os Dâw estão reduzidos a no máximo 100 pessoas e são facilmente visto embriagados em São Gabriel). Finalmente, os Nadöb, em contato permanente com 
os regatões, vivem do extrativismo nos rios Jurubaxi e Enuexi, afluentes da margem direita do Rio Negro.

Pela situação geográfica das localizações de suas aldeias, os Tukano foram descritos como índios-do-rio, enquanto os Hupdë foram descritos como os índios-da-floresta ou simplesmente Maku. A palavra maku é de origem Aruak e significa “sem fala ou sem [nossa] língua” ['ma = prefixo privativo / $\mathbf{a k u}=$ fala/língua]. Este termo foi inicialmente empregado pelos índios do grupo Aruak e, em seguida, passou a ser usado em toda região com um significado de atrasado, selvagem, sujo... etc. Hoje o termo tem um conteúdo depreciativo podendo, às vezes, ser até ofensivo. Já faz parte do português regional.

Uma das características dos Hupdë é a relação histórica, permanente e complexa, que estes mantêm com os índios da família lingüística Tukano oriental (Desana, Tuyuka, Piratapuia e Tariano principalmente) habitantes dos Rios Uaupés, Tiquié e Papuri. Esta relação interétnica faz parte da tradição dos povos desta região e merece ser preservada como forma de garantir o equilíbrio cultural dos povos do Alto Rio Negro. Esta relação já foi descrita como simbiótica, assimétrica e hierárquica, ou mesmo como relações patrão-cliente. ${ }^{11} \mathrm{O}$ comportamento dos Tukano, em relação aos Hupdë, é justificado através dos mitos que contam a origem dos povos da região. Os Hupdë, de acordo com versões Tukano do mito de origem, foram os últimos ${ }^{12}$ a saírem para este mundo, consequentemente são considerados como sendo inferiores, os menores de uma escala hierárquica ${ }^{13}$ que regula as relações interétnicas e, por isso sujeitos a trabalhos dito inferiores os quais apenas os clãs mais baixo na hierarquia fazem. Para ir mais além, a concepção de humanidade que os Tukano têm - como por exemplo, habitar nas margens dos rios, plantar a mandioca, casar com alguém que fale uma língua diferente - não encontra

11 Cf. também Athias (1995).

12 Segundo outras versões os Hupdë foram os primeiros a saírem da canoa-anaconda para ajudar os Tukano a descerem para margem. Nas versões Hupdë eles não vieram na canoa-anaconda e sim saíram de um buraco de pedra localizado na cachoeira, para uns em Ipano-ré para outros em Yauareté.

13 Não é minha intenção reduzir toda a peculiaridade e complexidade desta relação a intepretação do mito, há outros elementos que colaboram para esta visão dos Tukano vis-à-vis aos Hupdë. Os clã/sibs dos grupos indígenas da família Tukano também estão hierarquizados numa escala de senioridade. Os mais baixos na hierarquia também são considerados inferiores. 
correspondente entre os Hupdë. Estes fogem completamente deste padrão, por isso não são considerados como gente [mahsã] segundo os Tukano. Para os Tuka no os Hupdë são [pohsá] ou seja gente estragada. Hoje, são os Hupdë que ainda conservam bastante as tradições e expressões culturais dos povos da bacia do Uaupés.

Tradicionalmente, os Tukano sempre tiveram os Hupdë para fazer determinados serviços domésticos em troca de produtos de roças ou manufaturados. Em muitos dos casos, se dá uma troca efetiva, por exemplo: os Hupdë trocavam caça por mandioca, uma vez que são caçadores. Outro produto que os Hupdë usam para as trocas é o aturá, pois eles são responsáveis pela confecção do aturá [mãi], utilizado em toda a região por todos os grupos lingüísticos Tukano e Aruak. Essa especialização de produtos manufaturados é uma característica importante dos povos indígenas desta região outrora usados nas cerimônias de Dabucuri.

Tradicionalmente os Hupdë vivem em aldeias/grupo local com uma população de 15 até no máximo de 50 pessoas e geralmente cada grupo local compreende membros de um ou dois clãs. Cada grupo local é formado por vários grupos de fogo que representam a unidade mínima de produção e consumo. Os grupos locais estão geralmente localizados nas cabeceiras dos pequenos igarapés. Os grupos locais perambulam dentro de um perímetro tendo sempre como referência um dos igarapés, porém não migram além desta área determinada, senão por um espaço de tempo que pode ser por visitas aos sogros ou por um período de caçadas. Essas visitas são periódicas e representam um elemento importante na regeneração dos recursos renováveis da área de perambulação.

Em cada grupo local, existe a presença de um homem, mais velho, como referência e que lidera o grupo. Ele geralmente sabe contar a história dos ancestrais do clã. Não se pode confundir este homem de referência com o chefe (“capitão") que, em muitos dos casos escolhido em função do relacionamento com os missionários e outros agentes. Estes capitães articulam um sofrível português e são os intermediários entre os agentes não-índios com o mundo Hupdë. Eles, muitas vezes têm que saber interpretar muito bem para o grupo local as idéias e conceitos de missionários e outros agentes. Esta tarefa não é fácil. 
Os Hupdë como caçadores profissionais conhecem profundamente a floresta e trabalham pouco a agricultura extensiva como seus vizinhos, os Tukano. Estão dispersos em mais de 20 clãs. Cada um dos clãs reconhece um ancestral comum e um conjunto de práticas cerimoniais de conhecimento próprio de cada clã. Os casamentos se dão entre os diversos clãs. O casamento no interior de um mesmo clã é considerado incestuoso. O local de residência também difere dos Tukano. O homem pode residir tanto no grupo local do pai, (o mais comum de se encontrar), como também um homem casado pode residir no grupo local do sogro. E como todos os grupos indígenas do Alto Rio Negro praticam o Dabucuri e celebram o Jurupari até hoje.

\section{História do contato recente}

Os Hupdë-Maku apesar de serem sempre citados em documentos de cronistas, missionários, naturalistas, etnógrafos e antropólogos desde o final do século passado, o contato mais permanente com estes grupos é recente. Acho importante relatar sucintamente esta história para se tirar lições das diversas experiências que vem sendo executada na região.

O contato mais intenso de missionários e outros agentes da sociedade com estes grupos iniciam-se, na realidade, em 1950 apesar de inúmeras tentativas feitas anteriormente sem resultados. O padre Giaccone em seu livro sobre os Tukano de 1949 relata algumas das experiências que ele próprio havia tentado. $\mathrm{O}$ modelo evangelizador ${ }^{14}$ criado pelos missionários atraindo os Tukano para o internato não deu certo com os Hupdë que sempre prefiram ficar em seu território. Padre Giaccone conta que todos que os foram levados para o internato depois de algum tempo fugiam.

A iniciativa missionária de maior porte deu-se no início dos anos 50, com a abertura de uma estrada ${ }^{15}$ que ligaria o Rio Tiquié até Yauareté no Rio Uaupés. Esta estrada de 65 km iniciou-se no povoado Tukano Seãpahkara

\footnotetext{
14 Veja por exemplo o trabalho do Pe. Acionílio Bruzzi, O Método Civilizador Salesiano, em que ele descreve sucintamente as técnicas usadas pelos missionários na região.

15 Esta estrada não existe mais, a mata cerrada tomou conta.
} 
dihtara, hoje conhecido como Boca da Estrada no Tiquié, passando por um território bem tradicional Hupdë: os igarapés Traíra, Cabari, Dohdeh e Japu. Com a estrada construída, a Missão, então, pretendia instalar aldeias Hupdë ao longo da estrada com objetivos de mantê-las e assim facilitar o acesso dos missionários para suas atividades pastorais. É interessante escutar as estórias que os Hupdë, que participaram deste empreendimento, contam a respeito da experiência. Não deu certo.

Em 1962, foi criado o primeiro povoado-missão: Serra dos Porcos [Ton Haiã] ou Santo Atanásio, em um território considerado Hupdë. Recebiam frequentes visitas missionárias através de um caminho (4 horas), que sai de Ituim, povoado Tukano do Papuri, hoje apenas um sítio. Serra dos Porcos foi um laboratório de experiência. Ali atualmente existe um Posto da Funai e uma das pistas de avião da região. Foi também residência de missionários do Instituto Lingüístico de Verão e hoje conta com uma população de 280 pessoas. Para minimizar as tensões das disputas clânicas, nestes últimos anos este povoado-missão dividiu-se em três 'bairros' interligados.

Este modelo, de povoado-missão, será reproduzido em outros lugares durante as décadas seguintes. A idéia central deste modelo ${ }^{16}$ foi de concentrar vários grupos locais Hupdë em uma determinada área com apoio dos missionários e de outros agentes, com implantação de escolinhas tendo como professores indígenas não Hupdë. Na década de 70, o modelo é fortalecido a missão tem pessoal e recursos e assim são criados outros povoados-missão: Taracuá Ig., Fátima no Tiquié que não deu certo por estar completamente fora do território tradicional Hupdë. Wan guiar (Igarapé do alto Papuri), Cabari no Rio Japú e Nova Fundação localizada no igarapé Cucura em terras consideradas Desana. Muitos dos Hupdë, atualmente moradores em Nova Fundação, habitavam as cabeceiras do Cucura em território Hupdë.

\footnotetext{
${ }^{16}$ Pe. Norberto Hohenscherer (1986) descreve o modelo: “Com os Maku do Japu eu queria fazer um povoado modelo. Primeiro limpamos bem o igarapé para que no tempo da seca desse para chegar lá de motor. Muitos já tinham sidos batizados pelo Pe. Luís Di Stefano. Viviam em dois grupos que convidei a se juntarem num único povoado. Escolhemos um lugar bonito. Derrubaram e queimaram a mata. eu trabalhava no meio deles. Começamos a marcar as casas e levantar os esteios. Limpamos o campo e plantamos capim para levar gado mais tarde.”
} 
Em 1974, no Tiquié, a Missão inicia uma campanha com o seguinte slogan: "Somos todos missionários" incentivando os já evangelizados Tukano a irem evangelizar os Hupdë. Neste afã, outra grande aldeia Hupdë é incentivada a ser formada no estilo de povoado-missão, em Barreira no Tiquié. A história da criação deste povoado difere dos outros povoados-missão, foram trazidos pelos próprios Tukano para viverem ao lado de seu povoado.

No espaço de dez anos (1983-1993) os Hupdë de Barreira (Yuyudeh) mudaram três vezes a localização de sua aldeia. Hoje estão na margem do Rio Tiquiê ao lado de Barreira, convivendo no mesmo espaço que os Tukano. Isso só foi aceito pelos Tukano residentes em Barreira pelo fato destes mudarem todas suas roças para outra margem do rio. As antigas roças, hoje capoeiras, são geralmente usadas pelos Hupdë. Em termos de perspectivas nos anos vindouros posso ver duas alternativas possíveis: a) Os Tukano se mudarem para outra margem do rio ou b) Os Hupdë se retirarem deste local. Em 1984 este grupo local Hupdë estava estimado em 48, pessoas hoje estão com uma população de 110 pessoas enquanto os Tukano não chegam a 20 pessoas.

Todos estes povoados-missão, que atualmente são sete (Wanguiar, Serra dos Porcos, Cabari, Taracuá Igarapé, Barreira, Nova Fundação e Boca do Umari) concentram quase a metade da população total dos Hupdë. São nestes povoados onde se encontram focos de doenças como a tuberculose. Como se trata de povoados populacionalmente densos, fora da regra tradicional dos povos indígenas da região, abrigam diversos grupos locais fazendo com que a área de perambulação, fonte de recursos ao redor destes povoados logo sejam exauridas, provocando assim, falta de alimentos necessários para suprir as necessidades locais. Estes aglomerados favorecem as inúmeras disputas interclânicas gerando tensões desnecessárias se estes estivessem em grupos locais separados.

\section{Como estão os Hupdë ${ }^{17}$}

Como resultado desse processo a saúde das populações indígenas encontra-se em um lamentável estado de deterioração. A situação de saúde entre

17 As informações desta seção foram retiradas do relatório da SSL (Oliveira et al., 1997). 
os Hupdë caracteriza-se por um padrão onde ocorre o predomínio de doenças infecto-contagiosas, tais como a tuberculose, surtos de malária, infecções agudas do sistema respiratório e digestivo (gripes, pneumonias e diarréias), infecções de pele, tracoma, etc. A ocorrência destas afecções seguramente explica a mortalidade nestas áreas, bem como possui indiscutível custo social visto que acarreta a incapacitação temporária ou permanente par a execução de atividades quotidianas indispensável a sobrevivência.

Durante o período do levantamento foram visitadas as seguintes aldeias Hupdë: Serra dos Porcos (Ton Haiã), Cabari (Pindeh), Piracema (Hõpmõi), Taracuá Igarapé (Tatdeh), Nova Esperança (Boi-deh), Barreira (Yuyudeh), Nova Fundação (Pungdeh), Boca do Umari (Penddeh Nu). Foi possível perceber que o estado de saúde dessa população. Como se tratava de um levantamento, não foram feito exames clínicos em toda a população. Em povoados com grandes concentrações populacionais, como Santo Atanásio e Nova Fundação, que fogem aos padrões tradicionais, a ocorrência de doenças como a tuberculose e a desnutrição relacionadas à escassez alimentar está colocando em risco a sobrevivência desses povos.

Em Nova Fundação, foram detectados três casos de desnutrição grave em crianças na faixa etária de 1 a 7 anos. Ainda nessa comunidade foram realizadas duas remoções de emergência, sendo uma paciente com quadro de pneumonia grave e prolapso uterino total e outro paciente, adulto, com desnutrição grave e provável tuberculose. Este último morreu no Hospital de Taracuá.

Nas aldeias Hupdë visitadas existem várias pessoas com história pregressa de tuberculose, com tratamento interrompido e sintomáticos respiratórios. Especificamente, entre os Hupdë foram encontradas afecções oftálmicas importantes de etiologia indeterminada, sugestiva de tracoma, detectando-se dois casos de cegueira (amaurose).

Seguem uma tabela e um gráfico com os diagnósticos realizados pela equipe da SSL, durante a viagem de levantamento, realizado em 1996. 
Tabela 1. Diagnósticos realizados nas áreas Hupdë.

\begin{tabular}{|c|c|c|c|c|c|c|c|c|c|c|}
\hline FAIXA ETÁRIA & $0-11 m$ & $1-4 a$ & $5-9 a$ & $\begin{array}{l}10- \\
14 a\end{array}$ & $\begin{array}{l}15- \\
19 a\end{array}$ & $\begin{array}{l}20- \\
30 a\end{array}$ & $\begin{array}{l}30- \\
50 a\end{array}$ & $\begin{array}{l}50- \\
60 a\end{array}$ & $\begin{array}{c}60 a \\
+\end{array}$ & TOTAL \\
\hline \multicolumn{11}{|l|}{ DIAGNÓSTICO } \\
\hline Diarréia & 1 & 7 & 1 & & & 1 & & & & 10 \\
\hline Veminose & & 12 & 6 & & & 2 & 2 & & & 22 \\
\hline OMA/otalgia & 1 & & 3 & & & & & & & 4 \\
\hline IVAS & 2 & 12 & 1 & & & 4 & 4 & 2 & & 25 \\
\hline TBC Preqressa & & & & & & & 2 & 4 & 3 & 9 \\
\hline TBC Suspeita & & 2 & 1 & 1 & & 1 & 9 & & 4 & 18 \\
\hline TBC & & & & & & & & 1 & & 1 \\
\hline TBC Comunicantes & & 2 & & & & & & & & 2 \\
\hline Òftalmopatia à escl. & & & 1 & & 1 & 2 & 2 & 1 & 1 & 8 \\
\hline Conjuntivite & & 1 & & & & 2 & 1 & 1 & & 5 \\
\hline Amaurose & & & & & & & 1 & & 1 & 2 \\
\hline Impetigo & & 1 & 3 & & & & & 1 & & 5 \\
\hline Escabiose & 2 & 1 & & & & & 2 & & & 5 \\
\hline Outras afec Dermat. & & 2 & 1 & & & 1 & & 2 & & 6 \\
\hline Anemia & 1 & 5 & 2 & & & & 1 & & & 9 \\
\hline DPC & 1 & 6 & 2 & 1 & & 3 & 2 & & 1 & 16 \\
\hline Alt. Sist. Musc. Esq. & & & & & & & 1 & 1 & 1 & 3 \\
\hline Tunguiase & & 9 & 2. & 2 & & & & & & 13 \\
\hline Outros & & 3 & 2 & & 1 & 5 & 14 & 1 & & 26 \\
\hline TOTAL & 8 & 63 & 25 & 4 & 2 & 21 & 41 & 14 & 11 & 189 \\
\hline
\end{tabular}

O processo de contato com a sociedade envolvente é permeado por esta relação tradicional, que vem sofrendo profundas alterações, à medida que os ribeirinhos adotam práticas voltadas para a economia de mercado. A atual situação de saúde dos Hupdë remete a estas abruptas transformações que vêm recentemente ocorrendo. Sedentarizados, explorados e doentes os Hupdë assistem ao desmoronamento de sua base produtiva e de sua cultura, sem que lhes seja garantido o tempo para uma possível adaptação.

Apresentam um perfil epidemiológico distinto dos demais povos, típico das sociedades de contato recente. Convivem com alto grau de doenças transmissíveis, somadas às doenças endêmicas derivadas do processo de sedentarização, ambas associadas a graves deficiências nutricionais. Quanto à tuberculose, esta encontra-se em uma situação que beira a pandemia, como 
pode ser visto na amostra populacional atendida pela equipe da SSL (gráfico e tabela). Os Hupdë assistem a contaminação do solo e das fontes hídricas e sofrem com as doenças decorrentes; convivem com constantes surtos de afecções respiratórias e vêem o esgotamento dos recursos alimentares tradicionais. Este perfil fecha um círculo vicioso, ao condicionar graves e constantes perturbações nas atividades essenciais a subsistência deste povo.

As alterações nas condições de vida dos Hupdë, advindas das novas formas de convivência com os demais povos, relacionam-se estreitamente com este perfil. Ressalte-se, ainda, que os movimentos populacionais relativos aos demais indígenas acarretam sérios riscos a saúde deste povo. A situação é mais crítica ainda nos povoados-missão, nos quais se deterioram as condições de moradia e onde o consumo de caxiri, decorrente do excedente de produção de mandioca, e o consumo de aguardente, aparentemente configurados como um comportamento social reativo, chega a ser socialmente desestruturante.

Os Hupdë parecem não encontrar em suas representações culturais respostas adaptativas adequadas para todos estes eventos. São reticentes quanto a mudanças de vários dos seus hábitos de vida. Têm grande dificuldade de aderir a tratamentos decorrentes da medicina ocidental e mesmo a tuberculose parece ainda não ter uma concepção cultural apropriada. A tragédia total só não se configura devido à relativa cobertura vacinal destas populações, que necessita ser melhorada. A título de observação destaca-se que, de um total de 90 crianças examinadas, foram encontradas 17 crianças na faixa etária de 1 a 10 anos, sem marca de vacina BCG.

Como observou-se em entrevistas com os AIS, não se acredita que os agentes de saúde de outros grupos étnicos consigam atuar convenientemente junto a este povo, devido a modalidade tradicional de relação interétnica existente. Esta impressão foi reforçada durante nossa viagem pelas margens do Rio Tiquié.

Outras formas de assistência dificilmente se configuram, ainda que os Hupdë procurem, muitas vezes, as referências dos Hospitais Missionários da região, principalmente para tratamento de tuberculose, os quais, grande parte das vezes, são abandonados pelos mesmos.

Um trabalho de saúde junto a esta população deve se caracterizar por uma abordagem que leve em conta a multifatorialidade de sua situação de saúde e a especificidade da mesma em relação aos outros povos, devendo se pautar na multidisciplinaridade. Frente a esta situação, a formação de AIS 
Hupdë precisa ser diferenciada dos demais agentes da região. É preciso não somente conferir assistência preventiva e curativa a este povo mas também revalorizar sua rica cultura, reconstruir sua base produtiva e optar por um modelo educacional diferenciado e culturalmente adequado, que possa resgatar e reforçar a auto estima deste povo.

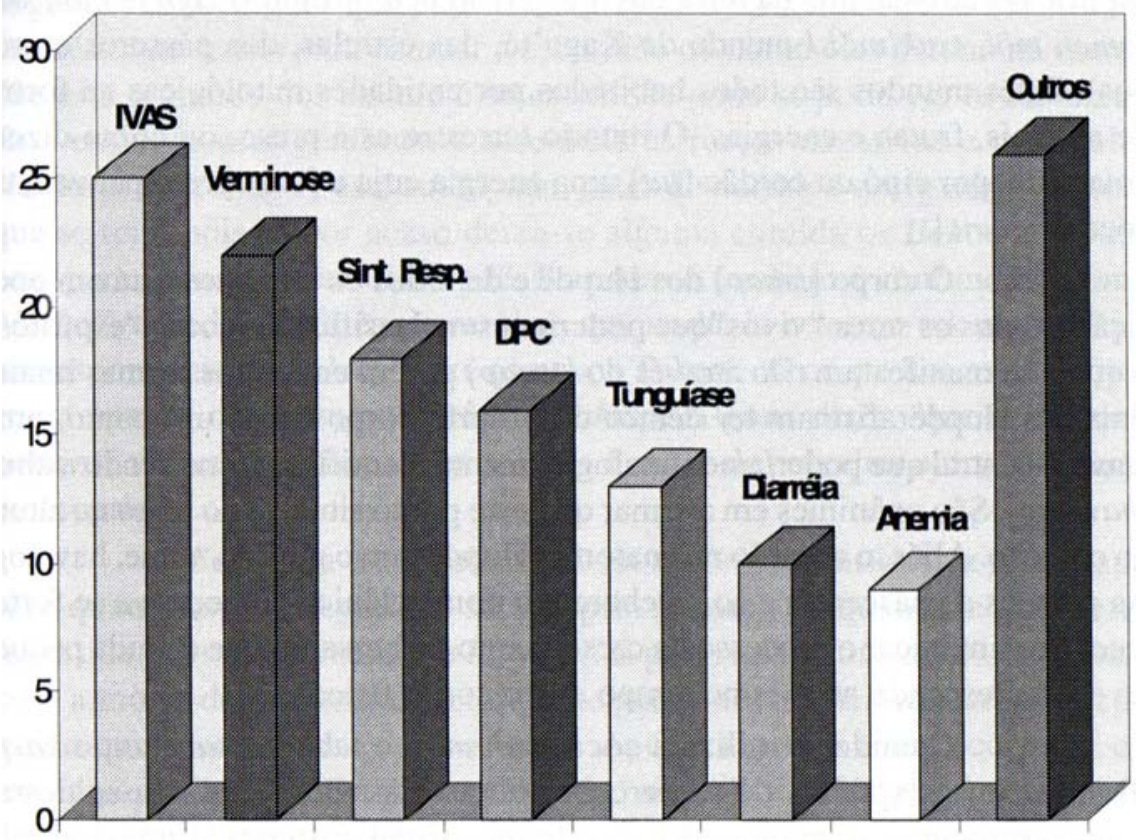

Gráfico 1. Diagnósticos realizados na Área Hupdë.

OBS: Sint. Resp.= Sintomáticos Respiratórios: este termo refere-se a indivíduos com tosse e expectoração há mais de três semanas e outros sinais e/ou sintomas sugestivos de TBC pulmonar.

\section{Bíin - o sistema médico Hupdë}

A representação de saúde e doença Hupdë está alicerçada na concepção de mundo e humanidade que estes possuem sobre a própria presença neste 
mundo terrestre. Esta cosmologia ${ }^{18}$ parte do princípio da existência de vários mundos sobrepostos uns aos outros. O mundo terrestre [txaa] é aquele em que nós (índios e não índios) vivemos com nosso corpo e está situado entre duas extremidades de um plano contínuo: do lado leste (mena), encontra-se o weró ip mõi, ou seja a casa do pai do sol e da lua ${ }^{19}$ e na outra extremidade oeste (porá) está o txa'tuí, onde nascem todos os rios e onde encontra-se o frio. Os outros mundos, estão localizados de uma forma vertical embaixo da terra e das águas (txak'mõi e openddeh - mundo dos umari e dos espíritos) outros acima da terra em direção ao céu infinito (Kagn'té mõi, we-romeh mõi, txuk'mõi / mundo de Kagn’té, das estrelas, dos pássaros e urubus). Estes mundos são todos habitados por entidades mitológicas na forma de animais, frutas e energias. O mundo terrestre está preso, ou como dizem amarrado, por cipó ou cordão [tut] uma energia cuja a fonte principal vem da coca [puhunc].

O corpo [tsaap] dos Hupdë e de todos os humanos está em oposição a todos os seres "vivos"que poderiam ser classificados como "espíritos” o quais se manifestam não através do [tsaap] porém em outras formas imateriais. Os Hupdë afirmam ter dentro do próprio corpo existe um ponto, uma energia central que poderíamos analogicamente identificar como sendo a alma [hawang]. São unânimes em afirmar que este ponto situa-se no peito na altura do coração. Aliás, o coração na anatomia Hupdë tem o mesmo nome, hawang. As pessoas ao nascerem e ao receberem o nome clânico começam a se fortalecer e assim iniciar o processo de crescimento do hawang (que é ainda pequeno e vai crescendo ao mesmo tempo em que o corpo físico).

Quando se utiliza a coca [puhunc], o tabaco [hunt] ou o karpi (Banisteriopsis sp.) ${ }^{20}$ pode-se perceber o hawang. O pajé utiliza-se destas plantas para sonhar e assim obter um diagnóstico de um doente. O pajé é o único que em um transe ou sonho percebe o hawang de seu paciente.

${ }^{18}$ Os elementos da cosmologia Hupdë apresentada aqui não vem de uma versão autorizada pelos Hupdë. São elementos que foram colhidos durante minhas pesquisas de campo entre os membros do clã txókwótnohkorntenre. Observa-se porém que existem diferenças, quando compara-se com outras versões de outros clãs, cf. também Reid (1979).

19 Diferentemente das outras línguas (Tukano e Aruak) da região os Hupdë designam tanto o sol como a lua com o mesmo nome: weró.

${ }^{20}$ Conhecido também como ahuaska, cipó, yagé. Está associado ao tut, o cordão ou cipó que interliga os mundos. 
No entanto outros Hupdë informaram que quando estão comendo o puhunc também pode perceber o hawang de outras pessoas. Porém em caso de diagnósticos apenas um iniciado ou um pajé pode oferecer.

Um Hupdë, além de ter seu tsaap (corpo) seu hawang (alma) possui também um baktup que poderíamos chamar de seu próprio fantasma ou sua sombra. O termo baktup ${ }^{21}$ é bastante usado e não encontramos um cognato em português que pudesse expressar a semântica do termo. Usa-se também este termo para chamar a escuridão ou como eles dizem: na escuridão está o mundo dos baktup é na escuridão onde se pode ver os baktupdë. Esta entidade está geralmente associada às forças negativas e malévolas. Na floresta quando se está acampado, antes de dormir é obrigatório comer o que se tem, pois se por acaso deixa-se alguma comida os Baktupdë aparecem para comer, dizem os Hupdë. Este termo também é confundido com o “diabo”, devido a influência católica que traduziu o termo tukano wãnti, o correspondente do baktup entre os povos Tukano. Os corpos dos animais possuem apenas o hawang não têm o baktup. Alguns dizem que o cachorro pode até ter seu próprio baktup pois ele é capaz de perceber outros baktupdë na escuridão.

Se a vida a consciência vem através do hawang a morte aparece quando a pessoa perde o seu próprio hawang ou quando o pajé determina que pessoa está sem seu hawang. É possível encontrar uma pessoa já com a morte determinada. Geralmente permanece deitada na rede esperando que o corpo pare de funcionar. Após a morte o tsaap (corpo) é enterrado o hawang vai para o mundo das “almas” que fica próximo ao mundo de Kagn’té e outros heróis, no alto do céu, enquanto o baktup (fantasma) permanece na terra ainda por um tempo, depois indo para um mundo que está localizado embaixo das águas, (porém podendo, de vez em quando aparecer na terra). A materialização do baktup está em todas as secreções do corpo tais como a urina, o suor, o catarro, o sangue e as fezes. É através destas secreções por onde todos o malefícios portanto as doenças podem penetrar.

Portanto a doença e a saúde estão no equilíbrio das duas forças ou energias existentes em nosso corpo: o hawang e o baktup. Cada iniciado conhece

21 Ao se escutar as interpretações semânticas deste termo há uma tendência para traduzir como espírito, porém pode se prestar a ambiguidades. 
as cerimônias de proteção e de fortalecimento do hawang. Todas as cerimônias de cura [Win dóhoité] invocam as forças da floresta para o fortalecimento do hawang e redução da influência do baktup sobre o hawang. Se um Hupdë está doente ou sente-se mal, é comum vê-los apontando primeiramente para o coração, mesmo que a doença esteja localizada em outro lugar do corpo. A doença então significa, em última análise, uma manifestação da fraqueza do hawang e um domínio maior do baktup sobre o corpo.

O sistema médico Hupdë é mediatizado por pessoas, geralmente do sexo masculino, iniciadas, possuidoras das “chaves” que abrem os diversos mundos na busca de interpretação para acontecimentos que se desenvolvem no txaa, na terra. Cada clã possui um conhecimento específico sobre a forma de se tratar. De acordo com os Hupdë tudo o que acontece aqui neste mundo de uma certa forma já aconteceu nos demais mundos em um tempo mítico. Portanto para tudo há uma interpretação e esta pode ser encontrada nas estórias de Kagn 'té (filho do osso), o demiurgo, criador de todas as coisas terrenas. O sistema médico é um sistema xamânico, tanto no que se refere às representações de saúde, doenças como em suas práticas terapêuticas.

O bi 'in é um termo que significa um conjunto de práticas rituais que vão desde ao um simples benzimento até as práticas mais complicadas de feitiçarias. Como todas estas práticas são realizadas através da palavra, geralmente este termo é traduzido como “sopro”, em alusão a forma de como o pajé fica recitando as fórmulas, num sussurrar de palavras com a uma cuia perto da boca. No português regional o termo soprar atualmente está associado a prática xamânica. O pajé geralmente usa uma pequena cuia onde é colocada água ou alguma erva para a pessoa ingerir, ou passar no corpo. O mais importante não está no conteúdo da cuia e sim no "sopro" no bi'in, no saber recitar a fórmula. Em muitos dos casos o pajé não precisa ver o paciente. Nos casos em que o pajé necessita ver o paciente, este se prepara antes, pode tomar o karpi quando necessário, porém sempre estão com o tabaco (hunt) e com a coca (puhunc). Ao examinar o paciente o pajé demora-se mais segurando o braço esquerdo para ver como está o baktup do indivíduo. Acreditam que no tsaap (corpo) existem dois pontos centrais onde deve-se procurar o equilíbrio. Geralmente a prática é fortalecer o hawang que está situado na altura do coração e diminuir o poder do baktup sobre o tsaap que, de acordo com a maioria 
dos Hupdë, está localizado no braço esquerdo. Este trabalho pode demorar horas. O paciente deve observar uma dieta para que haja o efeito desejado. As dietas geralmente contempla a interdição de comer assados, sal e pimentas. Outra interdição, quase sempre, imposta é não tocar mulher menstruada e abstinência sexual. O paciente geralmente deve permanecer deitado a maior parte do tempo.

Na realidade, o sistema médico Hupdë não difere do sistema médico ocidental do ponto de vista da operacionalização da relação doença/saúde $\mathrm{x}$ cultura. As diferenças entre a concepção da medicina Hupdë e a ocidental situam-se nas etiologias e nas práticas terapêuticas. A aceitação de muitos Hupdë de outras alternativas de cura não indica necessariamente, uma mudança nas representações das doenças ou uma diminuição do uso de práticas xamânicas nos casos de uma comprovada eficiência de cura. Os Hupdë continuam interpretar a doença através de sua concepção de mundo e das forças e energias operantes neste mundo terrestre.

O processo terapêutico nos sistemas médicos indígenas insere-se como um conjunto de interpretações sobre as doenças entre os indivíduos: as pessoas que tem um poder, as chaves da cura. O sistema médico Hupdë não pode ser considerado como autônomo e sim encontra-se sempre em processo de negociação. O sistema médico pode sofrer transformações quando ocorrem mudanças significativas no contexto político-social das populações Hupdë.

\section{Iuhut e baktup'pãt - gripe e tuberculose}

Nestes últimos meses, quando estava entre os Hupdë, procurei observar seu comportamento com relação a duas afeç̧ões que mais os afligem: a gripe e a tuberculose. A gripe é um terror: há um medo enorme das gripes. A gripe está associada aos brancos, ou seja, às coisas do branco, quanto à tuberculose não tenho tanta certeza dessa associação. Aliás a classificação entre doenças dos brancos e doenças dos índios, como geralmente encontramos na literatura sobre o assunto, parece não se aplicar para as populações Hupdë. Para eles, existem apenas as doenças que vem de fora, pois segundo eles, os Hupdë não têm doenças. Qualquer outra moléstia que apareça entre eles vem em primeiro lugar, do desequilíbrio entre as duas energias (baktup e hawang) e não 
entraria na classificação de doenças. Este desequilíbrio pode ser provocado i) primeiramente pelo próprio indivíduo que deixou de observar algum tabu ou desobedeceu alguma regra na convivência social (como por exemplo, o ato de sovinar); ou ii) o desequilíbrio é provocado por um ato de feitiçaria, para estes casos apenas os pajé pode ter um antídoto. Estes atos de pajelança geralmente são acompanhado por um certo tipo de veneno, ou algum elemento externo, pode ser um cabelo, um cigarro, etc. Para eles, certo tipos de venenos só têm efeito quando estão relacionados à palavra (encantamento) pronunciada por um pajé ou um outro iniciado.

Tuhu - significa literalmente catarro - é o nome genérico para gripe. As gripes sempre vêm do rio, e sempre alguém a transporta, em objetos, sacolas, lenços etc. Como o hawang das crianças ainda está em processo de crescimento elas são as mais afetadas. Em Yuyudeh no Tiquié, cheguei logo após uma epidemia de gripe muito forte, quando 22 pessoas morreram em 1983 naquela área. As casas estavam queimadas, muitos tinham ido isolar-se no interior da floresta e não havia nenhum bi'in que funcionasse. Havia uma conversa entre os velhos para identificar o porquê desta doença tão forte. Foi associada, na ocasião, à entrada de inúmeros garimpeiros no rio em direção ao garimpo. As máquinas, os barcos, que na realidade eram muitos, trouxeram tanta gripe. Em última instância, quanto maior a maleta maior é a gripe.

Tuhut, o catarro é uma secreção identificada como sendo do baktup e para eliminar o catarro as cerimônias são realizadas para neutralizar o baktup e isolar sua fúria. Existem na realidade algumas fórmulas xamânicas, mas são unânimes em afirmar que são para eliminar o catarro, porém para eliminar a gripe, eles precisariam saber mais. A gripe vem do mundo dos brancos e não existe uma identificação em nenhum mito, em nenhuma estória de Kagn’té, (talvez pela variedade das manifestações clínicas, uma gripe nunca é igual a outra). Em outras palavras, não existe uma compreensão geral sobre a gripe. Nos processos terapêuticos, geralmente, os pajés insistem em tirar tudo que vem do mundo do branco da casa e do paciente. Isso sempre provocou o espanto de missionários e outros agentes quando presenciaram em alguma aldeia uma criança gripada completamente despida.

A tuberculose, baktup'pãt (cabelo do baktup/cabelo do diabo) como os Hupdë a denominam, é uma doença recente, ainda está em elaboração no processo terapêutico Hupdë. A doença parece não estar associada ao mundo dos 
brancos como claramente está a gripe. Baktup'pãt na realidade é um termo usado nas línguas da região para identificar um conjunto de práticas xamânicas; quando aplicada por algum pajé o resultado é devastador. A pessoa que recebeu o malefício do Baktup'pãt morre exatamente como um portador de TB vem a falecer, ou seja, tossindo bastante e cuspindo sangue. Em outras palavras, o baktup’pãt é o último estágio da tuberculose.

Os Hupdë só conseguem diagnosticar uma tuberculose, geralmente na fase terminal. O processo inicial da doença - como o emagrecimento, o cansaço, as tosses crônicas - é visto independentemente e não está associado ao baktup'pãt. Os sintomas são tratados de forma isolada, dentro daquela mesma concepção de fortalecimento do hawang.

Como o baktup'pãt ocorre geralmente entre os adultos e velhos, a morte já é esperada. Para os Hupdë quando uma criança nasce, o hawang ainda é pequeno e precisa crescer na medida em que a criança cresce. Contrariamente, o baktup da pessoa já nasce grande e vai diminuindo de tamanho na medida em que a pessoa vai envelhecendo. O tamanho destas duas forças, residentes no tsaap, seguramente tem a ver na interpretação da tuberculose. Uma pessoa em idade bastante avançada que morre, mesmo que seja em consequência de uma tuberculose, morreu velho. Estes dizem nau'ná 'í que quer dizer "morreu bem” ou seja completou o ciclo, morreu com seu hawang grande e seu baktup bem pequeno.

Para retirar o baktup'pãt do corpo o pajé, segundo informaram, utiliza-se da farinha de mandioca em uma cuia juntamente com fórmulas de encantamento. A cuia é deixada embaixo da rede durante a noite. Eles dizem que quando chega a este ponto não tem mais cura. Cheguei a presenciar pessoas neste estágio e estas viviam normalmente deitadas na rede a espera que o seu corpo deixasse de funcionar. Dificilmente pode-se convencer uma pessoa, neste estágio, que poderá haver cura. O tratamento da tuberculose constitui-se hoje, um desafio para quem trabalha na área da saúde com estas populações.

\section{Doença de índio e doença de branco}

Para compreender o comportamento dos Hupdë em relação às doenças contagiosas, introduzidas entre eles através do contato com a sociedade envolvente, bem como as alternativas de cura propostas pela medicina ocidental, 
necessariamente teria-se que desenvolver instrumentos capazes de investigar e, em seguida, explicar o contexto sócio-cultural da experiência destas doenças. Por mais difícil que possa parecer, existe uma lógica no comportamento Hupdë em relação aos processos terapêuticos. O entendimento desta lógica facilitará o processo de transmissão de informação sobre o tratamento específico desta afecção.

A dificuldade encontra-se justamente em compreender o porquê de determinados comportamentos. A literatura sobre o assunto, como assinala Langdon $^{22}$ não oferece explicações sobre a escolha do processo terapêutico. Em diversas ocasiões pode-se perceber que a escolha de um determinado processo terapêutico, seja este via medicina ocidental ou medicina indígena entre os Hupdë obedece uma sequência de explicação e de interpretações do mito.

Durante nossa visita à área indígena para realizar o referido levantamento de saúde deparamos com algumas situações que merecem comentários. Em uma das aldeias encontramos um recém-nascido, já com sete dias, que não havia ainda defecado. O pai da criança, apesar de estar com um pajé em sua casa, resolveu chamar o médico para obter, quem sabe, outra explicação para o fato. Após o exame clínico verificou-se que não havia nada de anormal. Decidiu-se então, esperar mais um ou dois dias para se tomar uma decisão de remoção para um centro de referência. No outro dia a criança foi outra vez examinada pelo médico e enfermeiras e, novamente, chegou-se à conclusão que a criança estava bem e não havia nada que pudesse indicar uma intervenção médica de urgência ou mesmo uma remoção. No entanto, o pai da criança pediu-me que fosse buscar um outro pajé em aldeia próxima. Acatei a solicitação e nos dirigimos para tal aldeia em busca do referido pajé. Ao chegar à aldeia, o pajé não só já sabia o que estava acontecendo, como também tinha a solução para o problema do recém-nascido. Este pajé havia preparado a mãe do recém-nascido para o parto, porém na hora do nascimento, outro pajé foi requisitado. Ele deveria benzer para desatar o nó que estava no intestino e precisaria-se apelar para o mito para poder localizar o modo de fazer. Neste caso específico, a fórmula do encantamento estava na confecção das flautas de

${ }^{22}$ Cf. Langdon (1994, p. 118). 
Jurupari e confecção dos aparatos de espremer a mandioca no tipiti amarrado em pau com arumã (um tipo de cipó). O benzimento foi realizado e a criança defecou normalmente. ${ }^{23}$ Casos como esse legitimam para os próprios indígenas, de uma certa forma, a eficiência de seu sistema médico.

Um outro caso, também ilustrativo, da escolha seletiva do tratamento. Em uma aldeia, encontramos uma mulher Hupdë prostrada em sua rede há mais de 20 dias. Todos já diziam que ela estava morta. Ao ser examinada, constatou-se que ela encontrava-se com pneumonia dupla e um prolapso uterino total. Nos dirigimos ao chefe solicitando para que ela pudesse ser removida para um hospital próximo, o mais rápido possível (o que significaria, duas horas de caminhada no interior da floresta até a margem do rio e em seguida 3 horas mais, de motor de popa, até um aeroporto próximo e esperar um avião de salvamento. Todos diziam que ela já tinha morrido e que não tinha cura. Depois de uma tarde argumentando, conseguimos convencer que havia remédio para sua doença. Isso não significou a aceitação pacífica por parte dos Hupdë para a remoção. Foi preciso ainda, convencer o marido e os filhos. Ela foi transportada, recebeu o tratamento e voltou para aldeia. Não podemos dizer, neste caso, que os Hupdë aceitaram a eficiência do sistema médico ocidental através desta intervenção. Precisaria voltar à aldeia para ver as reações das pessoas quando a viram retornar.

Como se trata de dois sistemas médicos que convivem de diferentes formas, no caso da região do Alto Rio Negro, chamaria até de convivência pacífica, diferente de outras regiões, onde existe de fato uma oposição entre os sistemas médicos. Na realidade, o que existe é uma falta de compreensão total dos sistemas. Então, como levar a compreensão das etiologias? Como fazer entender aos Hupdë que o Baktup’pãt tem cura?

A literatura tem insistido na distinção entre doença de índio e doença de branco. A questão que se coloca aqui é justamente a validade desta classificação quando sabemos que a noção etiológica nos dois sistemas é baseada na percepção da cosmologia e de mitos. No caso, entre os Hupdë, este tipo

23 Encontramos na Mitologia Sagrada dos Desana -Wari Dihputiro Põrã, escrita por Fernandes e Fernandes (1996, p. 153), uma passagem no mito que retrata justamente a possibilidade de orações para este tipo de ocorrência. 
de classificação parece não existir. A escolha do tratamento não se dá porque existe uma compreensão clara do que sejam doenças de branco ou doenças hupdë. Aliás, por eles, fora as aspirinas e os remédios contra vermes, não procurariam a medicina ocidental, como de fato não procuram. Em outras palavras, a procura por um tratamento está associada e mergulhada em contextos culturais bem específicos. Os processos terapêuticos estão associados ao entendimento do mito e ao poder das palavras segundo o entendimento Hupdë.

A lógica na elaboração de representações das assim chamadas doenças-de-branco apenas poderá ser compreendida a partir do entendimento do mito e da cosmologia que em última instância, estrutura as relações no interior do grupo étnico e no conjunto das relações interétnicas da bacia do Alto Rio Negro. Portanto, a compreensão da existência de interpretações, justapostas ou paralelas, dentro de categorias como doença-de-branco e doenças-de-índios não é apoiada, na prática e nem pela a escolha dos processos terapêuticos.

\section{Referências}

ATHIAS, R. Hupdë-Maku et Tukano: les rélations inégales entre deux sociétés du Uaupés amazonien (Brésil). Tese (Doutorado)- Université de Paris X, Nanterre, 1995.

ATHIAS, R.; SELAU, G.; VERDUM, R. Levantamento da situação de saúde da população hupdë. São Gabriel da Cachoeira, 1984. Mimeografado.

BUCHILLET, D. Contas de vidro, enfeites de branco e potes de malárias. Brasília: UnB, 1995. (Série Antropologia, 187).

FERNANDES, A. C.; FERNANDES, D. M. Mitologia sagrada dos DesanaWari Dihputiro Põrã. São Gabriel da Cachoeira: ISA/FOIRN, 1996. (Coleção Narradores Indígenas).

HOHENSCHERER, N. História da evangelização dos Maku de Pari Cachoeira. Manaus: ISMA, 1986. 
LANGDON, E. Representações de doenças e itinerário terapêutico dos Siona da Amazônia colombiana. In: SANTOS, R.; COIMBRA, C. (Org.). Saúde e povos indígenas. Rio de Janeiro: Editora Fiocruz, 1994. p. 115-142.

OLIVEIRA, N. et al. Considerações sobre a saúde na região dos rios Uaupés, Papuri, Tiquié, Aiari e áreas Hupdë. São Gabriel da Cachoeira: Saúde Sem Limites, 1997. Mimeografado.

REID, H. Some aspect of movement, growth and change among the Hupdu Maku Indians of Brazil. Tese (Doutorado)-University of Cambridge, Cambridge, 1979. 